\title{
Contexto do Texto da Produção da Política dos Acordos de Cooperação Acadêmica Internacional de uma Universidade Federal
}

\author{
Context of the Text of the Production of the Policy of International Academic Cooperation \\ Agreements of a Federal University \\ Contexto del Texto de la Elaboración de la Política de Convenios Internacionales de Cooperación \\ Académica de una Universidad Federal
}

Recebido: 15/07/2021 | Revisado: 20/07/2021 | Aceito: 22/07/2021 | Publicado: 29/07/2021

\author{
Anna Claudia Sieverding Fabiano \\ ORCID: https://orcid.org/0000-0002-3181-1215 \\ Universidade Federal do Pampa, Brasil \\ E-mail:annafabiano@unipampa.edu.br \\ Elena Maria Billig Mello \\ ORCID: https://orcid.org/0000-0003-0366-3021 \\ Universidade Federal do Pampa, Brasi \\ E-mail: elenamello@unipampa.edu.br
}

\begin{abstract}
Resumo
Esta pesquisa objetivou analisar documentos de política que embasam os Acordos de Cooperação Acadêmica Internacional de uma universidade federal, a fim de verificar sua importância para a comunidade acadêmica e regional/local. É uma pesquisa documental que utiliza o contexto da produção do texto da política do Ciclo de Políticas de Stephen J. Ball. Com esse fim, a coleta de dados se deu por meio da análise em três documentos institucionais: Regimento Geral, Plano Institucional de Internacionalização e o Plano de Desenvolvimento Institucional (2019-2023), com aproximações na Análise Textual Discursiva. A Universidade reconhece a importância da internacionalização como forma de melhorar a qualidade do ensino, porém ainda falta um alinhamento institucional para a formalização das ações de acordos de cooperação. Também se percebe a universidade como um meio mobilizador de ações e produção de conhecimentos nos diferentes espaços sociais. Possibilitou a ampliação de conhecimentos sobre a internacionalização e fomentou reflexões acerca da inovação educacional como instrumento nos acordos de cooperação acadêmica internacional. Para isso, relevante é expandir e fortalecer as relações interinstitucionais, principalmente no país vizinho, impulsionando o desenvolvimento regional e local.
\end{abstract}

Palavras-chave: Educação Superior; Internacionalização; Cooperação Acadêmica Internacional; Ensino.

\begin{abstract}
This research aimed to analyze policy documents that support the International Academic Cooperation Agreements of a federal university, in order to verify their importance for the academic and regional/local community. It is a documentary research that uses the context of the policy text production of Stephen J. Ball's Policy Cycle. For this purpose, data collection was carried out through the analysis of three institutional documents: General Regulations, Institutional Plan for Internationalization and the Institutional Development Plan (2019-2023), with approaches in Discursive Textual Analysis. It was concluded that the University recognizes the importance of internationalization as a way to improve the quality of teaching, but there is still a lack of institutional alignment to formalize the actions of Cooperation Agreements. The university is also perceived as a means of mobilizing actions and knowledge production in different social spaces. It enabled the expansion of knowledge about internationalization and fostered reflections on educational innovation as an instrument that should be included in the International Academic Cooperation Agreements. For this, expand and strengthen inter-institutional relations, especially in the neighboring country, boosting regional and local development.
\end{abstract}

Keywords: Higher Education; Internationalization; International Academic Cooperation; Teaching.

\section{Resumen}

Esta investigación tuvo como objetivo analizar documentos de política que sustentan los Convenios Internacionales de Cooperación Académica de una universidad federal, con el fin de verificar su importancia para la comunidad académica y regional / local. Se trata de una investigación documental que utiliza el contexto de la producción del texto de políticas del Policy Cycle de Stephen J. Ball. Para ello, la recolección de datos se realizó mediante el análisis de tres documentos institucionales: Reglamento General, Plan Institucional de Internacionalización y Plan de Desarrollo Institucional (2019-2023), con enfoques en Análisis Textual Discursivo. Se concluyó que la Universidad reconoce la importancia de la internacionalización como vía para mejorar la calidad de la docencia, pero aún falta un 
alineamiento institucional para formalizar las acciones de los Convenios de Cooperación. La universidad también se percibe como un medio de movilización de acciones y producción de conocimiento en diferentes espacios sociales. Permitió ampliar el conocimiento sobre la internacionalización y propició reflexiones sobre la innovación educativa como instrumento que debe incluirse en los Convenios Internacionales de Cooperación Académica. Para ello, ampliar y fortalecer las relaciones interinstitucionales, especialmente en el país vecino, impulsando el desarrollo regional y local.

Palabras clave: Educación superior; Internacionalización; Cooperación académica internacional; Enseñanza.

\section{Introdução}

No nosso atual cenário de um mundo globalizado e em constantes mudanças e aperfeiçoamentos, torna-se cada vez mais necessário que as universidades priorizem e se insiram nos espaços de internacionalização, a fim de estabelecer relações com outras instituições estrangeiras. A cooperação acadêmica internacional é uma parte estratégica importante para o processo de internacionalização, já que hoje mais do que nunca as cooperações internacionais são cada vez mais frequentes, principalmente nas áreas de pesquisa e projetos científicos. É também uma estratégia que vem sendo desenvolvida entre os países a fim de alcançar objetivos comuns, envolvendo aspectos educacional, econômico, social etc. Por isso, os acordos internacionais entre os países têm se constituído como um meio para o desenvolvimento humano e a formulação de políticas de internacionalização. Marin (2004) descreve a internacionalização como o conjunto das atividades de cooperação internacional entre as instituições educacionais; sendo esse tipo de cooperação institucionalizada por meio de acordos multilaterais.

Para entender melhor, no Brasil, a internacionalização atinge um momento crucial, onde se faz necessário definir a existência ou não de fundamentos para a construção de políticas públicas para a internacionalização do sistema de Ensino Superior. A internacionalização constitui um dos mais importantes desafios frente ao novo século já que pode ser considerada uma das forças que mais impacta e define a educação superior. A internacionalização da Educação Superior pode ser entendida como um esforço sistemático de tornar a universidade mais enérgica no repensar das ações que deve adotar para encarar os desafios da globalização. (Morosini, 2006).

Bartell (2003) conceitua internacionalização como trocas internacionais relacionadas à educação e globalização como uma avançada fase no processo que envolve a internacionalização. A globalização e a internacionalização da Educação Superior compreendem as novas formas de relações entre pessoas, instituições e países no que se chama a nova era do conhecimento. Os termos globalização e internacionalização não são sinônimos, mas são processos que acompanham e são impactados pelas constantes mudanças sociais, especialmente com as novas formas de comunicação e com o avanço das tecnologias (Knight, 2012).

De acordo com Stallivieri (2016, p. 108), existem dez passos para se pensar a internacionalização e instituí-la em uma universidade, sendo eles: 1) reconhecer a importância e a necessidade da internacionalização; 2) desenvolver planos e metas para alavancar o processo da internacionalização; 3) institucionalizar o processo de internacionalização; 4) criar estruturas adequadas para o processo de internacionalização; 5) criar uma relação próxima entre as metas de internacionalização, a missão institucional e seus objetivos com relação ao ensino, pesquisa, extensão e gestão; 6) integrar a dimensão internacional no desenvolvimento de projetos das unidades e dos departamentos das instituições; 7) utilizar estratégias que incluam o ensino, a educação continuada, a pesquisa, a mobilidade acadêmica e administrativa e, principalmente, a inovação curricular; 8) desenvolver a avaliação sistemática da internacionalização de acordo com os padrões de qualidade, 9) estabelecer comitês de relações internacionais como agentes de mudanças institucionais levando em consideração as necessidades da instituição e 10) estabelecer um plano que dê visibilidade às atividades de internacionalização.

Assim, entende-se que a cooperação internacional se baseia na solidariedade, reconhecimento e apoio mútuos. O intuito é que propicie conhecimento e a disseminação de informações entre as instituições parceiras. Segundo Morosini (2011, p. 104): "Os Acordos bilaterais são programas que fomentam projetos conjuntos de pesquisa entre grupos brasileiros e 
estrangeiros. São financiadas missões de trabalho (intercâmbio de professores), bolsas de estudo (intercâmbio de alunos), além de uma quantia para o custeio das atividades do projeto".

A cooperação internacional ganha cada vez mais destaque no mundo globalizado, em que a busca por novas tecnologias, avanços científicos e informações relevantes faz com que as universidades, propulsoras de conhecimentos globais, se interessem mais e mais por um lugar proeminente nesse panorama global. As instituições ou nações que desenvolvem esse trabalho em conjunto, de cooperação, procuram a inserção na comunidade internacional e também na promoção da inovação. (Yilma, 1993, p. 29).

A partir das considerações anteriores, este artigo tem como objetivo analisar documentos de política dos acordos de cooperação acadêmica internacional de uma universidade federal, a fim de verificar sua importância para a comunidade acadêmica e regional/local.

\section{Metodologia}

Esse estudo se caracteriza por ser uma pesquisa documental, que, de acordo com Gil (2010): [...] utiliza-se de métodos e técnicas para apreender, compreender e analisar materiais dos mais variados tipos, que ainda não receberam um tratamento analítico, e que possibilitam observar indícios das ações, ideias, opiniões e formas de atuar e viver dos sujeitos".

Ademais, também foi utilizado o segundo contexto da produção do texto da política, do Ciclo de Políticas de Ball e colaboradores. Essa abordagem se faz importante para a análise das políticas educacionais no Brasil, assim como suas contribuições para a democratização da Educação Superior, desde as influências da política até sua implementação com seus efeitos no contexto da prática.

Na proposta Ball e colaboradores (1992) indicam que o foco da análise de políticas deveria recair sobre a formação do discurso de política e a interpretação que os profissionais atuantes no contexto da prática fazem ao relacionar os textos da política à prática. Um ciclo contínuo de contextos da política foi proposto pelos autores, sendo eles: contexto da influência, contexto da produção de texto, contexto da prática, contexto dos resultados (efeitos) e contexto da estratégia política. Os três primeiros contextos são os mais conhecidos.

O foco desta escrita, então, será o contexto da produção do texto da política, que diz respeito à elaboração de regras e normas que norteiam as instituições e que estão articuladas com "a linguagem do interesse público em geral" (Bowe; Ball; Gold, 1992, p. 20). Nesse contexto podem ser encontrados os textos legais oficiais e políticos, comentários formais ou informais sobre esses, pronunciamentos, entre outros.

Assim, nesta pesquisa, no contexto da produção do texto da política, fez-se a análise dos documentos legais que permeiam e caracterizam o processo de implementação dos acordos de cooperação acadêmica internacional numa universidade federal do RS, com aproximações na Análise Textual Discursiva (Moraes; Galiazzi, 2011). Os documentos analisados foram três: o Plano de Desenvolvimento Institucional (PDI), o Plano Institucional de Internacionalização (PII) e o Regimento Geral (RG). A análise dos referidos documentos foi realizada com a codificação e unitarização das seguintes categorias: acordos de cooperação acadêmica internacional (ACAI), internacionalização (I) e inovação pedagógica (IP). Nesse sentido, a codificação aparecerá na ordem em que cada excerto foi encontrado nos referidos documentos analisados, por exemplo, PDI-ACAI.2 indica o segundo excerto sobre acordos de cooperação acadêmica internacional encontrado no Plano de Desenvolvimento Institucional.

\section{Resultados e Discussão}


Os documentos legais da Instituição que apresentam os elementos específicos para a análise podem ou não ser interpretados da maneira correta, ou seja, os autores dos textos não podem ter controle sobre o significado que serão atribuídos aos seus textos, e isso leva à interpretação do contexto da prática. (Bowe; Ball; Gold, 1992). Como suporte à pesquisa documental se fez necessário buscar informações no Plano Institucional de Internacionalização, no Regimento Geral e no Plano de Desenvolvimento Institucional vigentes.

O Plano de Desenvolvimento Institucional vigente permite visualizar que toda a comunidade acadêmica deve integrar e se beneficiar das políticas de internacionalização. Historicamente, a instituição pesquisada tem diversificado o foco de práticas de internacionalização, não somente nas oportunidades de mobilidade. Assim como são distintos os programas de mobilidade, no recebimento de estrangeiros e envio de acadêmicos, a Universidade tem, da mesma forma, integrado suas práticas de ensino, extensão e pesquisa e gestão para além das fronteiras do Estado-nação.

Ressalta-se o crescente protagonismo da Universidade na ampliação e qualificação da promoção de novos convênios bilaterais e multilaterais e na consolidação daqueles já realizados, a exemplo do Grupo Coimbra de Universidades Brasileiras, a Associação de Universidades de Língua Portuguesa e do Fórum dos Assessores das Universidades Brasileiras para Assuntos Internacionais - Faubai.

O Regimento Geral da Instituição pesquisada é um documento que vai orientar o funcionamento institucional. Como observado em seu artigo $1^{\circ}$ : "O presente Regimento disciplina a organização e o funcionamento da Universidade [...], bem como estabelece a dinâmica das atividades acadêmicas e administrativas e das relações entre os órgãos da Instituição". (Universidade, 2010, p. 4).

Segundo o Plano Institucional de Internacionalização, são seus princípios: 3.1. Dignidade da Pessoa Humana; 3.2. Prevalência dos Direitos Humanos; 3.3. Defesa da paz; 3.4. Integração entre os povos; 3.5. Harmonia e reciprocidade nas relações entre instituições; 3.6. Desenvolvimento de regiões e países; 3.7. Transversalidade nas distintas competências educacionais e de gestão; 3.8. Oportunidades inclusivas e igualitárias; 3.9. Práticas de protagonismo e proatividade institucional.

Para a vivência desses princípios, ressalta-se a localização privilegiada da Universidade que, por estar situada em uma larga zona de fronteira com o Uruguai e a Argentina, tem na participação de estrangeiros em seus cursos uma presença que não pode ser ignorada. Tal presença é estimulada com programas específicos de ingresso de alunos fronteiriços, ou seja, aqueles que residem em cidades-gêmeas com as brasileiras, onde há unidades da Instituição. Uma das grandes ações que envolvem o ensino de graduação na atualidade envolve a possibilidade de dupla titulação, além da mobilidade acadêmica em ambas direções. A dupla titulação envolve, necessariamente, estudos e ações na busca de flexibilizar e compatibilizar os currículos, políticas multilíngues e alinhamentos interinstitucionais, a fim de propiciar ambos certificados. O Plano de Desenvolvimento Institucional prevê o apoio a programas de extensão interinstitucionais sob forma de consórcios, redes ou parcerias, bem como apoio a atividades voltadas para o intercâmbio nacional e internacional.

A Instituição, por meio de associações, promove ações que fomentam a internacionalização da Educação Superior como forma de desenvolver a cooperação acadêmica. São elas: a Associação das Universidades de Língua Portuguesa (AULP), ONG Internacional que promove a cooperação e troca de informação entre Universidades e Institutos Superiores. São mais de 140 (cento e quarenta) membros dos países de língua oficial portuguesa - Angola, Brasil, Cabo Verde, Guiné-Bissau, Moçambique, Portugal, São Tomé e Príncipe, Timor-Leste e Macau. A Associação Brasileira de Educação Internacional (FAUBAI) - criada em 1988, reúne mais de 180 (cento e oitenta) gestores ou responsáveis por assuntos internacionais e promove a integração e a capacitação dos gestores da área e o Grupo Coimbra de Universidades Brasileiras (GCUB) - uma associação civil, de direito privado, sem fins lucrativos, de caráter acadêmico, científico e cultural, composta por 77 instituições brasileiras de Educação Superior. Atualmente, a Instituição universitária pesquisada coopera com, 
aproximadamente, trinta instituições, objetivando: intercâmbio de discentes, docentes e técnicos e Cooperação técnica e científica.

No tocante à mobilidade acadêmica internacional, cabe ressaltar que, desde o ano de 2011, a Universidade já enviou 271 (duzentos e setenta e um) alunos para fora do País por meio dessa modalidade, além de receber diversos alunos de instituições estrangeiras pela participação em programas e convênios, conforme o quadro 1, a seguir:

Quadro 1 - Programas e convênios de mobilidade acadêmica da Universidade

\begin{tabular}{|c|c|}
\hline Programa & Graduação \\
\hline Programa Ciência sem Fronteiras (CsF) & 211 \\
\hline Programa Brasil-México (BRAMEX-GCUB) & 5 \\
\hline Programa Brasil Colômbia (BRACOL-GCUB) & 13 \\
\hline Programa Capes-Brafitec & 15 \\
\hline Programa Santander de Bolsas Ibero-Americanas & 23 \\
\hline Convênio Internacional & 4 \\
\hline
\end{tabular}

Fonte: Plano Institucional de Internacionalização - PII (2014 - 2018).

Por meio dos programas GCUB e do Santander de Bolsas Ibero-Americanas, a Universidade recebeu alunos de graduação para cursarem um período de mobilidade ou a pós-graduação completa; além do Programa Estudante-Convênio (PEC-G), do Ministério de Relações Exteriores, permitindo a participação de acadêmicos para cursarem a graduação completa.

Sobre a cooperação internacional, de acordo com o documento Plano Institucional de Internacionalização, a Universidade firmou acordos de cooperação acadêmica internacional com 24 (vinte e quatro) instituições estrangeiras.

A Universidade também conta com outros tipos de políticas que visam a internacionalização, como o Processo Seletivo para Fronteiriços. Essa ferramenta de fomento de integração entre Brasil e Uruguai, engloba o ingresso de estudantes de nacionalidade Uruguaia e Argentina nos cursos de graduação da Universidade em dois campi fronteiriços. Ademais, também existem outras ações como as políticas linguísticas voltadas aos estudantes que queiram cursar outros idiomas. Essas ações são desenvolvidas pelo Programa Idioma sem Fronteiras e o Centro de Línguas.

De acordo com a página da própria Universidade, o Programa tem como objetivo promover ações com vistas à Internacionalização do ensino superior brasileiro. O Programa é voltado para professores e alunos das instituições públicas de ensino superior, que têm acesso a diversos cursos de idiomas (presenciais e a distância) e a teste de proficiência gratuito. Já o Centro de Línguas é um projeto de extensão destinado a oferecer cursos de línguas estrangeiras à comunidade das regiões de Jaguarão e Rio Branco, no Uruguai.

Além disso, é interessante ressaltar que fora as ações e programas de cooperação internacional existentes na Instituição, há também o evento Salão Internacional de Ensino, Pesquisa e Extensão (SIEPE), que promove a cooperação acadêmica internacional. É um evento que conta com a parceria de instituições Uruguaias.

$\mathrm{Na}$ Universidade, a Diretoria de Assuntos Estratégicos e de Relações Institucionais e Internacionais (Daeinter) é o setor que é responsável pela parte da Internacionalização e acordos entre as instituições de educação superior. De acordo com a Universidade, a Daeinter é um: 
[...] órgão diretamente ligado à Reitoria, apresenta-se como instrumento de articulação, promoção e administração da Cooperação da Universidade com outras instituições de ensino, entes representativos de Estados como Consulados e Embaixadas, organismos internacionais governamentais e não governamentais. (UNIVERSIDADE, DAEINTER, 2020).

O órgão está situado na Reitoria, e, atualmente, o setor tem uma secretaria no campus fronteiriço. De acordo as informações do site da Daeinter, existem alguns acordos de cooperação acadêmica internacional vigentes, como pode ser visto no quadro 2:

Quadro 2- Acordos vigentes na Universidade

\begin{tabular}{|c|c|c|}
\hline País & Partícipe & Prazo de validade \\
\hline Argentina & Universidad de Mendonza & $01 / 10 / 2020$ \\
\hline Argentina & Universidad Nacional de Misiones & $01 / 10 / 2022$ \\
\hline Argentina & Universidad Nacional del Nordeste & vigente \\
\hline Espanha & Universidad de Zaragoza & vigente \\
\hline Estônia & Tallin University & Abril/2024 \\
\hline França & Chimie de Montpellier & Janeiro/2023 \\
\hline Inglaterra & The University of Nottingham & indeterminada \\
\hline Itália & Sapienza Università di Roma & $13 / 01 / 2020$ \\
\hline Itália & Università Degli Studi di Roma Tre & $03 / 11 / 2020$ \\
\hline México & Tamaulipas - UAT & vigente \\
\hline Portugal & Universidade da Beira do Interior & Março/2024 \\
\hline Portugal & Universidade de Coimbra & vigente \\
\hline Portugal & Universidade de Évora & vigente \\
\hline Portugal & Instituto Politécnico de Bragança & $17 / 12 / 2019$ \\
\hline Uruguay & Universidade de La Republica & indeterminada \\
\hline Uruguay & Universidad Tecnológica -UTEC & $04 / 05 / 2022$ \\
\hline Uruguay & Instituto Nacional de Investigação Agropecuária (INIA) & $25 / 07 / 2022$ \\
\hline
\end{tabular}

Fonte: Autora (2020).

No contexto dos documentos legais da Instituição, selecionou-se no Plano de Desenvolvimento Institucional (PDI), vigente para o período de 2019 a 2023, 60 (sessenta) excertos que continham as categorias: internacionalização, acordos de cooperação acadêmica internacional e inovação pedagógica.

Em relação aos acordos de cooperação acadêmica internacional foi encontrado o total de 12 excertos; em relação à inovação pedagógica, 38 excertos; e sobre internacionalização, 21 excertos.

Ao refletir sobre os excertos dos acordos de cooperação acadêmica internacional presentes no documento PDI, observa-se como a mesma é tratada: uma cooperação que destaca principalmente o desenvolvimento regional e a valorização do compartilhamento de saberes educacionais locais e internacionais, como pode ser observada no seguinte excerto: 
(...) Universidade "necessita ser responsiva às demandas locais e, ao mesmo tempo, produzir conhecimentos que extrapolam as barreiras da regionalização". (PDI-ACAI.2)

Nesse sentido, a Universidade aborda em seu documento a questão da cooperação internacional como tendo essa importância no estabelecimento de parcerias com diversos países e fortalecimento dos laços já existentes para uma integração regional mais fluída como pode ser observado a seguir:

(...) o processo crescente de cooperação internacional está contribuindo para ampliar o espectro de atuação, em um contexto de internacionalização, de prestação de serviço, de competitividade, de exigência de qualidade, de eficiência, de excelência acadêmica e de visibilidade e apoio à comunidade. (PDI-ACAI.3)

Assim, a cooperação internacional se mostra como uma importante ferramenta para a promoção da internacionalização do ensino superior, já que é por meio dela que estão sendo desenvolvidas a expansão e qualificação de programas acadêmicos, projetos de ensino, pesquisa e extensão.

Com a cooperação internacional, as instituições promovem a internacionalização universitária, almejando reconhecimento e visibilidade internacional, atraindo assim professores e pesquisadores renomados, como também estudantes de diversas partes do mundo. As ações cooperativas decorrem dos movimentos globais e, principalmente, da mobilidade de pessoas; contudo não há uma frequência ordenada e sistematizada, e para tanto, se torna iminente o levantamento de atividades que possam diagnosticar a posição da internacionalização nas instituições universitárias (Stallivieri 2017).

Também se nota que, além dos acordos de cooperação acadêmica, o PDI da Universidade trata também sobre a mobilidade acadêmica de estudantes e professores como a seguir:

Viabilização de programas e projetos de cooperação técnicos científicos e intercâmbio de docentes no País e no exterior, por meio de parcerias com instituições de pesquisa e desenvolvimento. (PDI-ACAI.6)

A mobilidade acadêmica também é vista como uma primordial ferramenta para a internacionalização do conhecimento. Há a busca pela formação e qualificação de profissionais para um mundo cada vez mais competitivo e onde as fronteiras não são mais vistas como um obstáculo e, sim, uma forma de repensar a construção do saber dentro da universidade. A Instituição pesquisada, assim como outras universidades, busca por meio da mobilidade acadêmica: "estabelecer uma amplitude nas dimensões intelectual, cultural, social, científica e tecnológica para a formação de cidadãos preparados para enfrentar os desafios do novo milênio" (Stallivieri, 2004, p. 38). Por isso, em um dos seus princípios da extensão disposto no PDI, a Universidade estabelece:

(...) Apoio a programas de extensão interinstitucionais sob forma de consórcios, redes ou parcerias bem como apoio a atividades voltadas para o intercâmbio nacional e internacional. (PDI-ACAI.7)

Como pode ser observado, há o apoio no sentido de aperfeiçoar os programas e acordos de cooperação acadêmica internacional e com isso, investir na qualificação de recursos humanos. A articulação entre a cooperação enternacional e ações de integração que permitam o desenvolvimento de intercâmbios também se faz presente. 
A mobilidade acadêmica inter e intrainstitucional permite ao discente cursar, temporariamente, componentes curriculares em outros campi e fazer o aproveitamento de estudos. Esses programas são regulamentados na Instituição e incentivados por meio de Acordos de Cooperação Internacionais, e a localização da Universidade é estratégica para a realização de alguns desses acordos que consideram a região de fronteira. (PDI-ACAI.10)

É interessante observar a importância dos acordos de cooperação acadêmica internacional no contexto da mobilidade acadêmica internacional e da internacionalização como uma estratégia que possibilita aos estudantes vivenciar experiências e compartilhar conhecimentos na formação universitária.

Esses documentos mostram que a Universidade tem o compromisso de promover a cooperação internacional e assim, fomentar as relações inter e intrarregionais. É destacada a importância de a Universidade fazer parte desse contexto internacional, promovendo a consolidação das relações com instituições estrangeiras de Educação Superior e o desenvolvimento científico, tecnológico e cultural.

Stallivieri (2004), em seu estudo sobre a cooperação internacional no Brasil, enumera alguns parâmetros que podem fazer parte de uma estratégia de internacionalização universitária. Entre eles, definir política de internacionalização; intercâmbio de estudantes, professores e gestores; inserir-se em redes de cooperação internacional; participar de projetos de alcance global; captar recursos de diferentes fontes de financiamento; coordenar e participar de eventos internacionais; participar de reuniões de organismos internacionais; coordenar convênios e acordos internacionais; oferecer títulos acadêmicos em conjunto com outras instituições; apoiar a formação de RH; captar talentos em áreas competitivas; divulgar informações sobre as oportunidades no exterior.

Já quando se trata da inovação educacional presente no documento, observa-se que ela é mencionada várias vezes. Na primeira vez que ela aparece já fica claro o compromisso da Universidade em promover a inovação nas suas atividades, como colocado no excerto:

Portanto, o PDI organiza-se de modo a propiciar as condições de atendimento a sua atividade fim, procurando repensar, constantemente, as práticas pedagógicas e acadêmicas, pesquisas científicas e tecnológicas, pós-graduação, extensão, inovação (...) (PDI-IP.1)

Leite (2012) corrobora com a compreensão de inovação na educação superior no sentido de que a "Inovação pedagógica não necessariamente, está relacionada a instrumentos inovadores, mas, sim, depende de olhares e de concepções que fundamentam o avanço na busca de rupturas, se forem necessárias, e de novos conhecimentos. (Leite, 2012, p. 36)”.

Voltando para o contexto em que se vive atualmente devido à crise da Covid-19, as universidades mais que nunca precisam pensar e repensar novas formas de saber, já que essa crise tornou possíveis inovações que antes não eram sequer levadas em consideração. Relevante pensar o mundo pós-Covid e o papel que as instituições de Educação Superior vão desempenhar nos próximos anos.

Também se observa nos documentos analisados que, muitas vezes, a inovação é vista somente como a inclusão de tecnologias na área da educação:

Empreendedorismo, produção e difusão de inovação tecnológica (PDI-IP.5)

Esse excerto foi retirado da parte em que estão listados os valores da Instituição, e não se trata na inovação educacional especificamente. É claro que é importante pensar na inovação de tecnologias que proporcionam aos professores, 
alunos e toda a comunidade acadêmica o uso de modernos recursos didáticos. $\mathrm{O}$ uso desses instrumentos também é considerado uma nova forma de ensinar, sendo assim, faz parte da inovação educacional. O que intriga é que a inovação educacional não se limita somente a instrumentos, e sim ela é definida também como ações, políticas que irão reformar os sistemas de ensino educacionais. Nesse aspecto, esse é um dos grandes papéis da universidade: fomentar ações por meio da inovação educacional, a fim de promover a qualidade do ensino superior e sua democratização. Pode-se perceber isso no excerto a seguir:

As universidades são responsáveis por ações associadas a: produção e difusão do conhecimento, pesquisa, extensão e cultura, inovação, ensino, formação e educação permanente. (PDI-IP.7)

Quando se trata da internacionalização, no PDI ela é mencionada mais vezes que as outras categorias. Na parte que retrata sobre os valores da Universidade, pode-se observar que ela é enfatizada como:

Desenvolvimento regional e internacionalização (...) (PDI-I.1)

Já é sabido que a internacionalização é uma importante estratégia para o avanço e compartilhamento das ciências nas universidades. A internacionalização na Educação Superior engloba políticas e programas de governo, com sistemas e subdivisões acadêmicas para lidar com a globalização. E também permite significante autonomia, iniciativa e criatividade no novo ambiente que se forma (Altbach, 2004; Morosini, 2006).

No trecho a seguir fica especificado o entendimento de internacionalização por parte da Universidade:

(...) A Universidade, por possuir unidades em cidades fronteiriças, tem a internacionalização como potencializador local e regional quando, por exemplo, oportuniza vagas a cidadãos estrangeiros residentes em cidades fronteiriças. Essa iniciativa mostra, com outros projetos de integração, que a internacionalização é uma rotina de promoção da paz e uma construção de um mundo onde as fronteiras passam a ser mais simbólicas que barreiras. Nesse contexto, o processo de internacionalização torna-se, de fato, essencial ao desenvolvimento da Universidade, enquanto concepção transversal em todas as suas áreas de atuação. Conforme almejado no Plano de Internacionalização, a política perpassa não somente o ensino, a pesquisa e a extensão, mas também a gestão da Universidade e a integração regional. (PDI-I.2)

A Instituição pesquisada, como já mencionada, tem unidades em cidades fronteiriças, possibilitando uma oportunidade única para que se estabeleça a internacionalização de fato, seja pela mobilidade acadêmica ou da cooperação internacional. A facilidade de poder atravessar a fronteira sem que seja preciso passar pela fiscalização aduaneira, vivenciando todos os dias a internacionalização com essa troca de culturas é algo que precisa urgentemente ser colocado como foco nas políticas da Universidade. É necessário que se dê mais atenção para essas facilidades e oportunidades que temos no nosso “quintal”. Está bem claro nos documentos que esse é um dos objetivos da Instituição, como pode ser observado:

No eixo Excelência Acadêmica, estão a preocupação com: ensino, pesquisa e extensão, acervo bibliográfico, inovação, interdisciplinaridade, manutenção e ampliação dos laboratórios de ensino, Internacionalização e outras. (PDI-I.4)

O espaço para a criatividade parece estar nas mãos das instituições que escolhem as melhores formas para se adaptar ao ambiente acadêmico internacional, acomodando, dessa forma, diferentes graus de autonomia e iniciativa (Knight, 1997; 
Scott,1998; De Wit, 2002). Por isso se torna claro a importância da formulação de políticas e estratégias que possam contribuir para o avanço da Internacionalização dentro da Universidade.

Mais uma vez a internacionalização aparece como um dos princípios do ensino, como observado a seguir:

Pesquisa como princípio educativo, como referência para o ensino na graduação e na pós-graduação, em que a pesquisa e a inovação atendam demandas regionais, assim como a internacionalização seja um eixo presente em ambos os níveis. (PDI-I.7)

A internacionalização não pode ser vista como um processo de ações isoladas. Ela é dinâmica e envolve todas as esferas do ensino, pesquisa e extensão; e precisa ser pensada como fundamental para o desenvolvimento da universidade em âmbito nacional e internacional.

Entre as práticas pedagógicas inovadoras, a Universidade se compromete com a promoção de: tecnologias, pedagogias e metodologias ativas e processos que envolvam e promovam a internacionalização. (PDI-I.13)

Com isso, observa-se que mais uma vez a Universidade retrata em seus documentos a importância da internacionalização, e a tem como um instrumento de inovação para o ensino. A internacionalização se torna cada vez mais um processo necessário para que a Educação Superior se alinhe ao nosso mundo globalizado, a nossa sociedade do conhecimento.

Destaca-se também o desenvolvimento dos programas de mobilidade acadêmica interinstitucional que permitem ao discente cursar componentes curriculares em outras IES, no Brasil ou no exterior, como forma de vinculação temporária pelo prazo estipulado no convênio assinado entre as Instituições, assim como receber discentes de outras instituições, promovendo a internacionalização e a relação com diferentes culturas. (PDI-I.16)

Como já foi colocado, um importante instrumento de internacionalização nas universidades é a mobilidade acadêmica. Stallivieri (2009) explica que a mobilidade de estudantes fortalece a produção de vínculos transnacionais, formando conexões e redes de produção de conhecimento universal. Essas redes intensificam a interação entre comunidades científicas de diferentes partes mundo. Por exemplo, é possível identificar os alunos que viajaram para o exterior em mobilidade acadêmica no exterior na Universidade pesquisada, como expresso no quadro 3, a seguir: 
Quadro 3 - Número de estudantes na Universidade em mobilidade no exterior.

\begin{tabular}{|l|c|c|c|c|c|c|c|c|c|}
\hline \multicolumn{7}{|c|}{ Número de estudantes em mobilidade no exterior } \\
\hline \multicolumn{1}{|c|}{ Programa } & \multicolumn{7}{|c|}{ Ano em que o aluno partiu para mobilidade } \\
\hline & & & & 5 & 2 & 4 & 3 & 1 & 15 \\
\hline $\begin{array}{l}\text { Brasil Colômbia } \\
\text { BRACOL-GCUB }\end{array}$ & & & & & & & & \\
\hline $\begin{array}{l}\text { Brasil México BRAMEX- } \\
\text { GCUB }\end{array}$ & & & & & 1 & 2 & 4 & 3 & 10 \\
\hline CAPES-BRAFITEC & 2 & 5 & & 5 & 2 & 1 & 1 & & 16 \\
\hline $\begin{array}{l}\text { Ciência sem Fronteiras - } \\
\text { CAPES }\end{array}$ & 4 & 99 & 56 & 6 & & & & & 165 \\
\hline $\begin{array}{l}\text { Ciência sem Fronteiras - } \\
\text { CNPq }\end{array}$ & 17 & 18 & 10 & 1 & & & & & 46 \\
\hline $\begin{array}{l}\text { Convênio Internacional/ } \\
\text { sem bolsa }\end{array}$ & & 1 & & & & 1 & 1 & 6 & 9 \\
\hline $\begin{array}{l}\text { Santander de Bolsas Ibero- } \\
\text { Americanas }\end{array}$ & 5 & & 8 & 6 & 1 & 3 & & 2 & 25 \\
\hline Total & 28 & 123 & 74 & 23 & 6 & 11 & 9 & 12 & 286 \\
\hline
\end{tabular}

Fonte: DAEINTER (2019).

Assim, verifica-se que a Universidade, com bolsas e programas por meio dos acordos de cooperação, conseguiu enviar alunos para o exterior, na chamada Mobilidade outgoing.

A mobilidade acadêmica inter e intrainstitucional permite ao discente cursar, temporariamente, componentes curriculares em outros campi e fazer o aproveitamento de estudos. Esses programas são regulamentados na Instituição e incentivados por meio de Acordos de Cooperação Internacionais, e a localização da Universidade é estratégica para a realização de alguns desses Acordos que consideram a região de fronteira. (PDI-I.17)

No excerto acima é mencionado os acordos de cooperação acadêmica internacional também como uma forma de internacionalização, juntamente com a mobilidade acadêmica. A cooperação é um instrumento eficaz nas estratégias de internacionalização, que devem ser inscritas nos planos de desenvolvimento institucional (PDI, 2019 - 2023)

A seguir, apresenta-se outro documento da Universidade, o Plano Institucional de Internacionalização (PII) de 2019. As categorias observadas nesses documentos foram as mesmas: acordos de cooperação acadêmica internacional, inovação pedagógica e internacionalização. Analisou-se, inicialmente, a categoria relativa aos acordos de cooperação. Como mencionado a seguir, é um dos objetivos dos acordos de cooperação:

Construir a internacionalização como política institucional perpassando todos os níveis de atuação através da cooperação bilateral e multilateral com instituições internacionais, para ampliação do programa de mobilidade de toda a comunidade 
Acadêmica. (PII-ACI.1)

Ao pensar nos acordos de cooperação acadêmica internacional e na internacionalização na Universidade, torna-se primordial pensar em uma política de internacionalização concreta, que englobe toda a estrutura da instituição como seus objetivos, sua visão e também o que está estabelecido no Plano de Desenvolvimento Institucional (PDI).

Stallivieri (2017) cita informações essenciais a serem consideradas quanto aos acordos de cooperação e a internacionalização: localização geográfica; linguagem de comunicação; potencial de publicações científicas em revistas internacionais, assim como a capacidade de participação em pesquisas de níveis mundiais; competência em estabelecer e manter parcerias internacionais; participar e gerir programas globais de mobilidade acadêmica para docentes, pesquisadores, discentes e corpo técnico; possibilidade de receber pesquisadores internacionais e desenvolver projetos de pesquisa a nível Internacional, e também sua manutenção com recursos disponíveis; não obstante os recursos financeiros, humanos e de infraestrutura necessários à manutenção do plano estratégico.

Ainda no referido documento PII consta como importante:

(...) Compreender a internacionalização como eixo transversal e com a importância de política internacional sempre esteve presente no planejamento institucional. (PII-I.1)

A política de internacionalização deve estar alinhada aos objetivos da Universidade, levando em consideração um plano estratégico bem formulado para que o objetivo maior se concretize, um ensino de qualidade para todos. A internacionalização se torna um compromisso da Instituição com a sociedade globalizada, mesmo trazendo inúmeros desafios para seu desenvolvimento e implantação. Todo o processo de internacionalização necessita estar regulamentado dentro da Universidade, permitindo um alcance muito maior dos resultados fazendo com que a mesma seja um instrumento essencial para o crescimento da Instituição e a democratização do ensino.

Pode ser observado um dos objetivos gerais da internacionalização no documento pesquisado:

(...) Promover cooperação internacional, bilateral e multilateral. (PII-I.2)

Está claro no Plano Institucional de Internacionalização a preocupação da Universidade em cooperar com outras instituições e países. A cooperação internacional tornou-se um fator fundamental para o incremento da ciência brasileira e mundial, justamente nesse período em que a educação está sendo considerada prioritária nas sociedades que se internacionalizam e são impulsionadas rapidamente devido à era da globalização, que por si só, diminui fronteira, tornando qualquer tipo de contato mais rápido, fácil e eficaz. (Westphal, 2014, p. 55).

(...) Comissão de Relações Internacionais do Fórum de Pró-Reitores de Extensão das Instituições de Ensino Superior Públicas Brasileiras destaca a importância crescente de um programa de internacionalização da extensão universitária. Um programa para a extensão representaria um salto qualitativo imensurável na vida das comunidades envolvidas com os projetos, bem como transformaria a formação dos estudantes. Tais membros da comunidade Acadêmica estariam em contato com diferentes culturas, ao mesmo tempo em que estariam experimentando metodologias de trabalhos similares, estimulando o desenvolvimento de relações internacionais baseadas na Cooperação e fraternidade entre os povos. (PII-I.5). 
Fica evidente a importância da internacionalização como uma estratégia necessária para a construção de uma política pública que visa a melhoria do ensino no país, e também para a consolidação dos acordos de cooperação acadêmica internacional entre as nações, buscando parcerias e interesses em comum. Como afirma Stallivieri (2004):

A cooperação internacional, julgada como um reflexo da realidade em razão do avanço das comunicações e diante da necessidade de superação das distâncias e das barreiras agora inaceitáveis aos países passou a auxiliar as universidades a serem melhores e mais competitivas através da definição de políticas claras, apontando objetivos, viabilizando meios, disponibilizando recursos, tanto humanos como materiais, e atuando com base em uma agenda positiva para a internacionalização. (Stallivieri, 2004, p.8).

Especificado no eixo da gestão, o documento PII traz:

Neste eixo prioriza-se a busca por desenvolvimento de acordos com instituições de diferentes países objetivando ampliar a gama de parcerias efetivas e consolidar os acordos com países com os quais a Universidade já possui cooperação. Atualmente a Universidade coopera com aproximadamente 30 instituições, objetivando: intercâmbio de discentes, docentes e técnicos e cooperação técnica e científica. (PII-I.6)

E mais uma vez se leva em consideração a posição geográfica da Universidade para que os acordos possam ser firmados com países vizinhos. A cooperação na fronteira pode se tornar uma das formas mais eficazes de se atingir os objetivos em comum.

Desde sua criação, a Universidade firmou acordos de cooperação internacional com 24 Instituições de Ensino Superior estrangeiras, a fim de estimular a cooperação acadêmica internacional. (PII-I.8)

É importante destacar mais uma vez que, em tempos pandêmicos e de cenário político cada vez mais instável, a sustentabilidade dos acordos de cooperação depende cada vez mais de parceiros estratégicos que fomentem e valorizem o crescimento das instituições e da sociedade.

O espaço fronteiriço binacional em que a Instituição se localiza, por exemplo entre Santana do Livramento, no Brasil, e Rivera, no Uruguai, está acostumado a colaborações básicas entre instituições, como na área da saúde, da segurança policial, dos serviços aduaneiros, sociais e culturais. Entretanto, a falta de marcos regulatórios, não raras vezes, esvazia os objetivos das ações e não aproveita esta capacidade de relacionamento. (Rodriguez-Miranda; Galaso; Goinhex; 2016).

A seguir, na figura 2, pode se observar a existência de redes de projetos com suas organizações e vínculos de Santana do livramento e Rivera. As cores dos círculos indicam as diferentes nacionalidades das organizações e o "tamanho" desses significa a quantidade de vínculos de cada organização. Quanto maior a organização, mais vínculos ela possui com outras organizações. 
Figura 2 - Redes de projetos em Santana do Livramento e Rivera

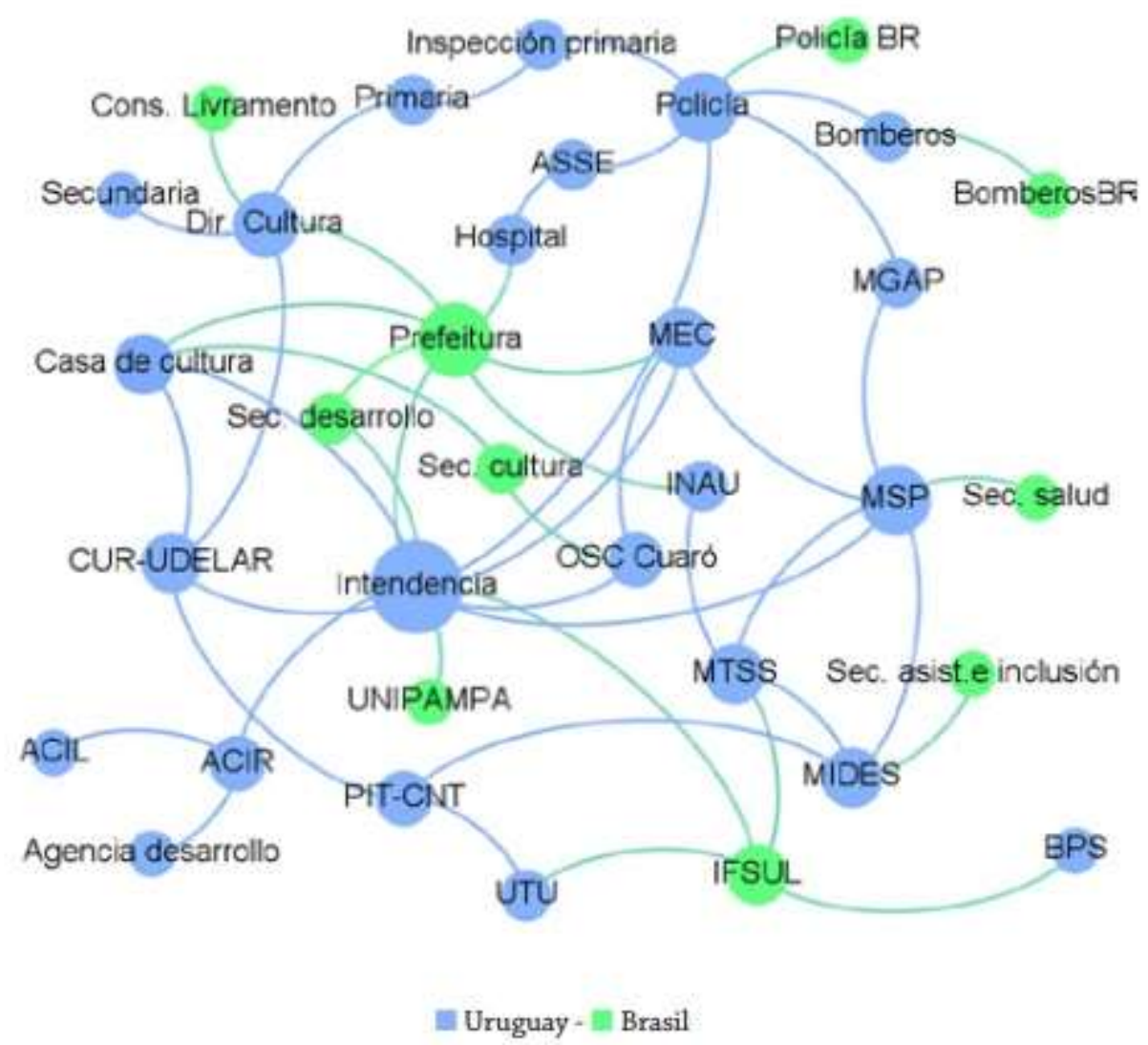

Fonte: Rodriguez-Miranda; Galaso; Goinhex (2016, p. 86).

Assim, é possível notar que para a realização de projetos, as organizações uruguaias possuem mais vínculos do que as brasileiras, pelo fato da maior articulação do lado uruguaio do que do lado brasileiro. Ainda, é importante ressaltar que existem fortes vínculos entre as instituições fronteiriças. (Rodriguez-miranda; Galaso; Goinhex, 2016).

Ainda consta no documento a importância dessas parcerias com a menção ao evento Salão Internacional de Ensino, Pesquisa e Extensão (SIEPE):

Há 10 anos a Universidade promove a cooperação acadêmica internacional através do Salão Internacional de Ensino, Pesquisa e Extensão (SIEPE). Em 2017, com o propósito de alavancar o processo de cooperação com o Uruguai, o evento foi sediado pelo campus de Santana do Livramento e, de forma inédita, organizado em parceria entre IES brasileiras e uruguaias. (PII-I.9)

Assim, por dois anos consecutivos o SIEPE foi realizado e, com isso, foram firmadas parcerias com instituições brasileiras e uruguaias, por exemplo, o IFSul e a UTEC. Ressalta-se a importância da cooperação internacional na formação de cidadãos capazes de prover um mundo mais igualitário e plural, já que é nas instituições de Educação Superior que a cooperação se desenvolve para o ensino e a pesquisa cresça e se fortaleça.

De acordo com Didriksson (2008), as mudanças para a valorização do conhecimento deveriam vir da cooperação e da integração; tal situação leva as instituições de Ensino Superior a buscar novas estruturas organizacionais que facilitem o acesso a um conhecimento de valor social. Por isso, a Universidade se mostra disposta a fortalecer os laços com os países vizinhos, a 
fim de proporcionar a concretização de um espaço que busque valorizar a integração regional por meio de um ensino superior de qualidade.

No último documento analisado, o Regimento Geral da Universidade, poucas foram as observações acerca da cooperação internacional e inovação. Sobre internacionalização especificamente nada é mencionado. A seguir serão observados excertos que mencionam acordos de cooperação:

Art. $8^{\circ}$. Dada a estrutura originária multicampi, a Universidade observará as seguintes diretrizes de organização: Cooperação entre as Unidades Universitárias e os Órgãos Complementares, visando unidade de ação no desenvolvimento do Plano de Desenvolvimento Institucional e economicidade na gestão do corpo docente e técnico-administrativo em educação, dos recursos materiais, tecnológicos e financeiros. (RG-ACAI.1)

Sendo que a palavra cooperação aqui empregada se refere à relação da reitoria e todas as unidades da Universidade constituindo seus campi.

SEÇÃO II - DOS RECURSOS FINANCEIROS Art. 129. Os recursos financeiros da Universidade serão provenientes de: VII. Convênios, acordos e contratos celebrados com entidades ou organismos nacionais ou internacionais. (RG-ACAI.2)

Sabe-se que a cooperação entre as nações e a internacionalização são caminhos para um ensino de maior qualidade e para isso, deve-se elaborar políticas que tratem especificamente acerca da internacionalização e incluir nos processos de ensino e aprendizagem.

Para atingir e manter a qualidade na perspectiva internacional ressalta-se a relevância da mobilidade entre países, instituições de Educação Superior e o mundo do trabalho. Também o documento resultante da Conferência Mundial sobre Ensino Superior, em 2009, registra a importância da dimensão transfronteriça do Ensino Superior como meio para a construção de uma educação de qualidade. (Unesco, 1998).

Já se tratando da inovação pode-se observar o seguinte trecho:

SEÇÃO II - DA IMPLEMENTAÇÃO DAS ATIVIDADES Art. 121. A consecução das atividades estabelecidas nos objetivos institucionais se dará pela: III. busca contínua de técnicas e métodos inovadores; (RG-IP.1)

É notável que a Universidade, assim como outras instituições, preocupa-se com a questão da inovação visando ensino de maior qualidade. A busca pela inovação interfere em processos de formação curricular, métodos pedagógicos e todas as atividades que possam ser desempenhadas dentro da universidade, por professores e alunos. Trata-se de um novo paradigma de Educação Superior, em que a internacionalização é vista como um importante instrumento para viabilizar o processo de democratizar o acesso ao ensino, proporcionar novas formas de ensinar pautadas no pensamento crítico unindo o local e o global.

No que se refere à questão da internacionalização nada é mencionado no documento institucional analisado. Como uma instituição que deseja fazer de seu objetivo a internacionalização como uma nova forma de desenvolvimento e crescimento, falta ainda uma iniciativa para consolidar e definir políticas de internacionalização e ações que atendam as necessidades da Universidade. É necessário que haja uma visibilidade dentro e fora da Instituição, e um choque de conscientização por parte de todos os segmentos da Universidade para que se possa concretizar na maior urgência possível. 
Nesse contexto, a internacionalização pode ser vista como uma forma de preparação dos indivíduos para o engajamento em um mundo mais globalizado capazes de prover uma sociedade mais inclusiva e solidária (Altbach, 2009); sendo necessária que ela seja prioridade na elaboração das políticas institucionais das instituições de Ensino Superior, e com isso fomentar e consolidar as relações intra e interinstitucionais por meio dos acordos de cooperação acadêmica.

É importante relembrar qual é a preocupação fundamental que enfrenta o sistema educativo: melhorar a qualidade da educação pública para que todos aprendam mais e melhor. (Veiga, 2003). Para provocar essa mudança no sistema educacional deve-se levar em consideração a inovação pedagógica, que está cada vez mais ganhando espaço e rearticulando a organização do sistema com base no "novo". Como retrata Veiga (2003, p. 274): "A inovação procura maior comunicação e diálogo com os saberes locais e com os diferentes atores e realiza-se em um contexto que é histórico e social, porque humano.”.

Nada mais inovador do que fomentar as relações internacionais numa instituição de ensino superior por meios dos acordos de cooperação acadêmica internacional. As autoras Morosini e Dalla Corte (2021 apud Morosini, 2021, p. 77-78) salientam que, no contexto da internacionalização da Educação Superior, é relevante a atenção aos países do Sul Global que muito têm a contribuir nos currículos dos cursos de graduação e pós-graduação, enriquecendo assim a atuação profissional para que se valorizem os conhecimentos multiculturais locais.

\section{Considerações Finais}

Para atender ao objetivo da pesquisa que resultou nesta escrita, foram analisados os documentos de política dos acordos de cooperação acadêmica internacional de uma universidade federal, a fim de verificar sua importância para a comunidade acadêmica e regional/local.

Nesse sentido, foram analisados os documentos oficiais: Regimento Geral, Plano de Desenvolvimento Institucional e a Política Institucional de Internacionalização da Universidade investigada, a partir dos descritores: acordos de cooperação acadêmica internacional, internacionalização e inovação pedagógica.

A análise permitiu observar que os acordos de cooperação acadêmica internacional presentes nos documentos são incentivados pela Universidade como uma forma de desenvolvimento e integração regional, fomentando, assim, as relações inter e intrarregionais. A inovação também se faz presente nos documentos, demonstrando que a Universidade tem como um de seus compromissos a promoção da inovação em seus espaços. Nesse sentido, enfatiza-se o papel formador da Universidade uma vez que além de fornecer a formação profissional, a IES também é responsável pela produção de pesquisas básicas e aplicadas que impulsionam a inovação em diferentes áreas do conhecimento, assumindo um papel central na sociedade do conhecimento do século XXI. (Miura, 2006).

É sabido também que a internacionalização tem seu papel central quando se trata de instrumentos potencializadores para o avanço das universidades no compartilhamento de saberes acadêmicos e científicos. Observa-se que mais uma vez a Universidade retrata em seus documentos a importância da internacionalização, e a tem como um instrumento de inovação para o ensino.

O processo de internacionalização é transversal e envolve toda a comunidade acadêmica. É algo que precisa ser construído conjuntamente com todos os setores e não somente com a assessoria internacional ou uma gestão específica. Ao longo do estudo, ficou evidente que a cooperação acadêmica internacional é vista como um instrumento de inovação no processo de internacionalização do Ensino Superior. Com vistas à consolidação efetiva dos acordos, muitas ações têm que ser tomadas, tanto por parte da comunidade acadêmica como de outros setores envolvidos na Instituição.

Com os resultados, percebeu-se a Universidade como um meio mobilizador de ações e produção de conhecimentos nos diferentes espaços sociais. Desta maneira, espera-se que Universidade valorize e aproveite o cenário binacional 
multicultural em que se encontra para que se fortaleçam as parcerias, contribuindo para formação de espaços mais democráticos e colaborativos entre os países.

Como sugestão para estudos futuros, no âmbito da internacionalização e dos acordos de cooperação, indica-se a necessidade de maior aprofundamento nos textos da política e como na prática esta política é implementada, para ampliação e visibilidade das ações e relações interinstitucionais e internacionais na Fronteira, no campo da Educação Superior. Sendo assim, minimizar questões que envolvam dificuldades na hora de firmar parcerias e acordos de cooperação acadêmica internacional.

\section{Referências}

Altbach, P. G. (2004). Globalization and the university: myths and realities in an unequal world. Tertiary Education and Management, Boston, EUA, 10 (1), $3-25$.

Altbach, P. G. (2009). Educación superior comparada: el conocimiento, la universidad y el desarrollo. Universidad de Palermo - UP.

Bartell, M. (2003). Internationalization of universities. A university culture-based framework. Higher Education, Manitoba, Winnipeg, 45(1), 43-70.

Bowe, R.; Ball, S. J.; Gold, A. (1992) Reforming Education and Changing Schools: case studies in policy sociology. London: Routledge.

De Wit, H. (2002). Internationalization of Higher Education in the United States of America and Europe: a historical, comparative, and conceptual analysis. Greenwood Studies in Higher Education.

Didriksson, A. (2008). Contexto global y regional de la educación superior en América latina y el Caribe. In A. L. Gazzola \& A. Didriksson (Eds.), Tendências de la Educación Superior en América Latina y el Caribe (pp. 21-54). Caracas, Venezuela: IESALC-UNESCO. http://iesalc.unesco.org.ve/index.php?option=com_fabrik\&view=details\&formid=2\&rowid=78\&lan g=ES

Gil, A. C. , (2010).Como elaborar projetos de pesquisa. Atlas.

Knight, J. (1997). Internationalization of higher education: a conceptual framework. In: Jane Knight and Hans de Wit (Eds). Internationalization of higher education in Asia Pacific Countries. Amsterdam: European Association for International Education.

Knight, J. (2012) Student Mobility and Internationalization: trends and tribulations. Research in Comparative and International Education, Oxford, 7(1), 2033.

Leite, D. B.C. (2012). Desafios para a Inovação Pedagógica na Universidade do século 21. Revista da FAEEBA - Educação e Contemporaneidade, Salvador, v.(21), 29-39.

Marin, A. (2004). Internacionalização da Educação Superior no Brasil: relatório final. Belém: Associação de Universidades Amazônicas - UNAMAZ. 1101.

Miura, I. K. (2006). O processo de Internacionalização da Universidade de São Paulo: um estudo de três áreas do conhecimento. 2006. Tese (Livre-docência em Administração) - Faculdade de Economia, Administração e Contabilidade de Ribeirão Preto (FEA-RP), Ribeirão Preto.

Moraes, R. Galiazzi, M. C. (2011). Análise textual discursiva. Ijuí, Brasil: Editora Unijuí.

Morosini, M. C. (2006). Estado do conhecimento sobre Internacionalização da educação superior: conceitos e práticas. Educar. Curitiba, (28), $107-124$.

Morosini, M. C. (2011). Internacionalização na produção de conhecimento em IES brasileiras: Cooperação Internacional tradicional e Cooperação Internacional horizontal. Educação em Revista, Belo Horizonte,27(1), 93-112.

Morosini, M. C. ; Dalla Corte, M. (2021) Internacionalização da Educação Superior. In: Morosini, M. (org) Enciclopédia Brasileira da Educação Superior EBES. [recurso eletrônico]. Porto Alegre: EDIPUCRS. Recurso on-line. RIES/Pronex; v.(10-11).

Rodrigez-miranda, A.; Galaso, P.; Goinhex, S. (2016). Entre ló local y ló regional: ciudades de frontera y integración regional transfronteriza em Uruguay. Segunda parte. In: MAZZEI, Enrique (Ed.). Las sociedades fronterizas: visiones y reflexiones. Montevideo: Universidad de la Republica Uruguay.

Stallivieri, L. (2016). V Fórum de Internacionalização da UNESP. Bauru, São Paulo.

Stallivieri, L. (2017).Compreendendo a Internacionalização da educação superior. Revista de Educação do Cogeime, Belo Horizonte, 26(50), 15-36.

Stallivieri, L. (2004). Estratégias de Internacionalização das Universidades brasileiras. Caxias do Sul: EDUCS.

Scott, P. (Ed.) (1998). The Globalization of Higher Education. Society for Research into Higher Education and Open University Press.

Unesco - United Nations Educational, Scientific and Cultural Organization. (1998).Primer estudio internacional comparativo sobre lenguaje, matemática y fatores asociados em tercero e cuarto grado Santiago, Chile: UNESCO/Laboratorio Latinoamericano de Evaluacion de la Calidad de la Educación. 
Research, Society and Development, v. 10, n. 9, e43610918292, 2021

(CC BY 4.0) | ISSN 2525-3409 | DOI: http://dx.doi.org/10.33448/rsd-v10i9.18292

Universidade. Regimento Geral. 2010. Bagé. https://sites.Unipampa.edu.br/consuni/files/2017/12/3-regimento-geral-nova-versao.pdf

Universidade. Plano de Desenvolvimento Institucional 2019 - 2023. Bagé. https://sites.Unipampa.edu.br/proplan/files/2019/09/pdi-2019-2023-publicacao.pdf

Universidade. Plano Institucional de Internacionalização 2018. Bagé. https://sites.Unipampa.edu.br/propesq/files/2019/01/plano-InternacionalizacaoUnipampa.pdf

Universidade. Relatório de Gestão 2020. Bagé. https://sites.Unipampa.edu.br/proplan/files/2021/04/rgi-2020-final.pdf

Veiga, I. P. A. (2003). Inovações e Projeto-pedagógico: uma relação regulatória ou emancipatória? Caderno Cedes, 23(61, Campinas.

Westphal, A. M. S. (2014). Egresso da primeira Chamada do Programa “Ciência sem Fronteiras": reflexos no sistema educacional brasileiro (Learning with outcomes). 2014. 120p. Dissertação (Mestrado em Educação) - Universidade Católica de Brasília (UCB), Brasília.

Yilma, T. (1993). Transfer of Technologies in Molecular Biology to Developing Countries. In Tzotzos, George (ed.). Biotechnology R\&D Trends - Science and Technology for Development- NYAS, N.York, USA. 